\title{
RELEASE FROM PI: Comparison of traditional and computer modules in an experimental psychology laboratory
}

\author{
SUSAN M. BELMORE \\ University of Kentucky, Lexington, Kentucky 40506
}

\begin{abstract}
RELEASE FROM PI is a computer-controlled participatory module designed for use by students in laboratory sections of an experimental psychology course. It allows the student subjects to trace their recall performance across sets of four lists when the fourth list changes in physical characteristics or semantic category. The performance of students participating in this computer module was compared with that of students receiving a traditional procedure with a human experimenter. All other aspects of the laboratory session were equated as much as possible. The recall data showed that the traditional procedure produced better recall and greater release with a semantic shift. However, both methods resulted in roughly equivalent learning (as measured by multiple-choice questions) and student evaluation ratings. Implications for the use of computers in instruction and research are examined.
\end{abstract}

In 1980, the psychology department at the University of Kentucky began a long-term project designed to strengthen our advanced undergraduate laboratory offerings, especially the basic course in experimental design. This project resulted in the establishment of a computer learning laboratory featuring seven terminal learning stations (Apple II microcomputers) coordinated by a central hard disk (see Lowe, 1983). Our basic strategy for software development in the experimental psychology course involved participatory demonstrations in which the student acts as a subject and generates behavioral data (see Spivey, 1983). This participatory experience is embedded in an educational matrix that includes printed handouts, class discussions, study questions, data analysis, and written laboratory reports.

This paper describes a locally developed module that demonstrates the release from proactive inhibition (PI) procedure and summarizes the results of a direct comparison between this computer-controlled module and traditional versions of the procedure. This comparison was motivated in part by the lingering suspicion that the considerable effort invested in developing computer-assisted instructional modules may result in laboratories that teach the material as well as, but no better than, traditional means of instruction. Since

This project was supported by NSF Grant SER-8005325 to the Department of Psychology (R. C. Dillehay, Project Director) and matching funds from the University of Kentucky. A catalog of instructional materials is available from CAUSE, 115 Kastle Hall, Department of Psychology, University of Kentucky, Lexington, Kentucky 40506. Reprints of this paper, a diskette containing the RELEASE FROM PI program for the Apple II microcomputer, and copies of all supplementary materials (student's guide, instructor's guide, and multiple-choice questions) are also available upon request. There will be a nominal charge to cover the costs of matcrials and reproduction. the RELEASE FROM PI module replaced a traditional laboratory module, it provided an opportunity for a direct experimental test of this question. Half of the students enrolled in experimental psychology in fall semester, 1982, were assigned to the computer-controlled module, and the other half were assigned to an equivalent traditional procedure controlled by a human teaching assistant. The present paper reports three types of data from this comparison: (1) the mean recall performance of the student subjects, (2) performance on knowledge questions administered before and after participation, and (3) students' evaluative ratings of interest and enjoyment.

\section{Description of the Phenomenon}

Release from PI refers to the facilitatory effect of a shift in list characteristics in a multilist learning situation (Wickens, 1972). The decline in recall performance typically seen over successively presented lists (presumably reflecting the buildup of PI) is reversed (a "release" from PI) for a final list that is different in some significant way from the preceding lists. Wickens' (1972) interpretation of this effect assumes that any change that produces a release effect must represent an encoding dimension in human memory. He reports that semantic changes (e.g., differences in taxonomic category or semantic differential ratings) usually produce larger amounts of release from PI than do physical changes (e.g., color, location, or size of the words).

\section{Description of RELEASE FROM PI}

RELEASE FROM Pl is a computer-controlled demonstration that allows the student to observe the phenomenon with both a physical shift (screen location) and a semantic shift (taxonomic category). While Wickens' (1972) original procedure used word triplets in a short- 
term memory distractor task, this module uses an alternative method involving free recall of eight-item lists. The demonstration consists of a total of 16 lists: four sets of 4 lists each. This allows a within-subjects factorial design with two independent variables: shift condition (experimental or control) and shift type (physical or semantic). Each set of four lists thus represents one of the four conditions of the experiment: physical shift, physical control, semantic shift, semantic control. The physical shift involves a change in location (from the center to the upper right-hand corner of the screen), and the semantic shift is a change in taxonomic category (from animals to foods).

In order to allow each student to experience each condition, the module was originally conceived as a completely within-subjects procedure. Even though the list conditions are not identified until the student has finished recalling all eight lists using the order of conditions given above, this arrangement compromises the data considerably. The program can easily be modified to allow shift condition to be varied between subjects. This is recommended for the instructor who has a strong interest in achieving representative data.

The student's participation in this procedure is supplemented by a printed handout containing references, background information about the phenomenon, a description of the design, and tables and graphs to be filled in with either individual or group data. The module is also accompanied by two sets of six multiplechoice questions testing for knowledge of the phenomenon and specific aspects of the design.

\section{METHOD}

\section{Subjects}

The subjects were 74 students enrolled in the experimental psychology course. The students were enrolled in four different laboratory sections (approximately 18 students per laboratory) taught by two graduate assistants. One laboratory section for each graduate assistant was randomly designated to participate in the computer module, and the other was assigned to the traditional version.

\section{Procedure}

Following instructions, the students in both conditions saw the stimulus words in each list presented one at a time ( $3 \mathrm{sec}$ each) and then recalled as many words as possible from that list immediately following presentation. Attempts were made to equate the experiences of students in the traditional and computer-controlled versions of RELEASE FROM PI as much as possible. Both sets of students received exactly the same sequence of events, except for the collection and scoring of the memory data. In the computer module, instructions and stimulus words were presented on the terminal screen. Since there were only seven terminals available, some students worked in teams of two to three per terminal. Students typed in their recall responses on the keyboard and copied down summaries of their performance after every set of four trials. Students in the traditional condition received oral instructions in a group setting, viewed stimulus words mounted on individual slides, wrote their recall responses on blank sheets of paper, and scored their own performance after all 16 lists. One additional difference between the versions was the amount of time they required: The computercontrolled procedure took approximately $25 \mathrm{~min}$, whereas the entire presentation-recall-scoring procedure in the traditional version took almost $1 \mathrm{~h}$. In all cases, the students participated in a class discussion of their experiences, tabled and graphed their own data, completed pre- and posttest knowledge questions, and completed a standardized module evaluation form (modeled after an instrument developed at the University of Florida).

\section{RESULTS}

\section{Recall Performance}

The dependent measure was the mean number of words recalled on each trial in each of the four sets. The results for both computer and traditional versions are shown in Figure 1. A four-way repeated-measures ANOVA was performed on 52 subjects ( 26 in each condition) for whom complete data were available. This analysis showed that, overall, students in the traditional version recalled more words per list (mean $=6.75)$ than students in the computer version $($ mean $=5.28)[\mathrm{F}(1,50)$ $=91.23, \mathrm{MSe}=4.92 \mathrm{]}$. (This difference may reflect the stricter spelling criterion used in the machine scoring condition.) The semantic sets generally produced better recall than the physical sets $[F(1,50)=15.88, M S e=$ $2.26]$; there was no significant effect for shift vs. control conditions. Recall tended to decline from Trial 1 to Trial 3 (mean $=6.2,6.0$, and 5.8, respectively) and then rose to the level of the second trial by Trial 4 , producing a main effect of trials $[F(3,150)=5.20, \mathrm{MSe}=1.14]$.

The critical comparison for the release-from PI phenomenon involves Trial 4 in the shift and control conditions. Inspection of performance on Trial 4 alone indicated that neither the computer nor the traditional version produced a release in the physical shift condition, but both showed evidence of release in the semantic

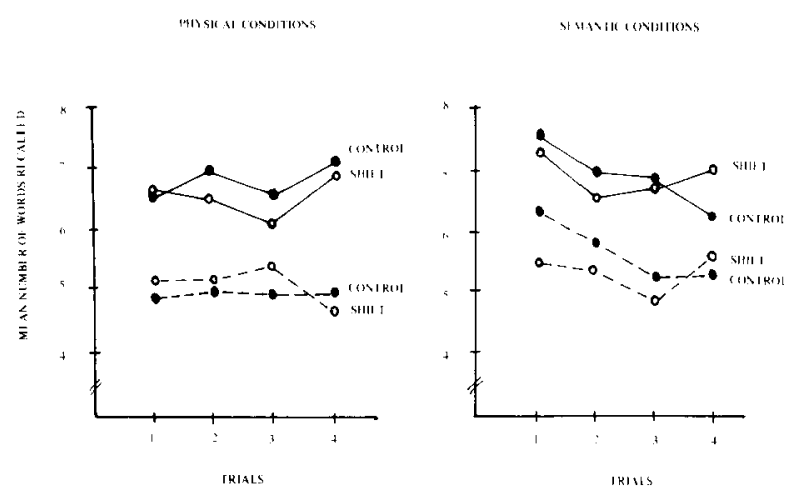

Figure 1. Release from PI as a function of physical and semantic shifts for traditional (solid lines) and computercontrolled (dotted lines) modules.

Table 1

Comparison of Scores on Knowledge Questions

\begin{tabular}{lcc}
\hline & \multicolumn{2}{c}{ Percent Correct } \\
\cline { 2 - 3 } & Pretest & Posttest \\
\hline Traditional & 41 & 73 \\
Computer Controlled & 43 & 75 \\
\hline
\end{tabular}


Table 2

Comparison of Responses on Feedback Questionnaire

\begin{tabular}{|c|c|c|}
\hline Question & $\begin{array}{l}\text { Tradi- } \\
\text { tional }\end{array}$ & $\begin{array}{l}\text { Com- } \\
\text { puter }\end{array}$ \\
\hline 1. Doing this module gave me a better understanding of the material. & 1.94 & 2.18 \\
\hline 2. I learned new material by participating in this module. & 2.14 & $2.56^{*}$ \\
\hline 3. I enjoyed doing this module. & 2.40 & 2.20 \\
\hline 4. I felt rushed during the module. & 3.34 & $2.72 *$ \\
\hline 5. The material was presented clearly and concisely. & 2.48 & 2.38 \\
\hline 6. Too much material was covered. & 3.48 & 3.51 \\
\hline 7. I could have learned the same things by listening to a lecture. & 3.66 & 3.41 \\
\hline 8. I enjoyed this module more than listening to a lecture. & 1.94 & 2.00 \\
\hline 9. The material was presented in less time than would have been possible through a lecture. & 3.06 & $2.26^{*}$ \\
\hline 10. Overall, I thought this was a good module that should be used with other students taking this course. & 2.03 & 2.15 \\
\hline
\end{tabular}

shift condition. The amount of release from PI on Trial 4 was computed as suggested by Wickens (1972). The traditional version showed nearly twice as much release $(45 \%)$ as the computer version $(28 \%)$ in the semantic shift condition. Although this is less release than Wickens has observed under similar conditions, the direction of findings is clearly consistent with the observation that larger shifts are found with semantic changes.

\section{Knowledge Questions}

A total of 58 students completed both the pretest and posttest knowledge questions, 26 from the traditional laboratory and 32 from the computer-controlled module. As seen in Table 1, both groups showed large and approximately equal gains in knowledge as a result of their participatory laboratory experience. Both versions produced over $30 \%$ increase in accuracy of response, but students apparently learned an equal amount from either version.

\section{Feedback Questionnaire}

Data from the feedback questionnaire were available for 74 students, 35 from the traditional module and 39 from the computer-controlled version. The mean response to each question on a scale from 1 (strongly agree) to 5 (strongly disagree) is shown in Table 2. Only three questions were significantly different $(p<.05)$ in $t$ tests for uncorrelated means. Students seemed to feel that they learned somewhat less in the computer-controlled condition than in the traditional version. Their responses to two other questions reflected the differences in total presentation time in the two versions. However, there were no significant differences on other questions reflecting enjoyment and interest.

\section{DISCUSSION}

The evaluation activities described here allowed a direct comparison of traditional human-controlled and computer-controlled versions of the same laboratory module in a fairly well controlled experimental design. The pedagogical question was: are our students learning more (or at least enjoying it more) from computerassisted methods in instruction? There is an interesting paradox here. As researchers, our increasingly common use of computer-controlled procedures (for example, in text processing experiments) is based on the assumption that subjects' experiences are not qualitatively different in significant ways from their experience in traditional human-controlled experiments. While this is a plausible assumption, it is largely assumed rather than tested at this time. As educators, however, we hope, and, indeed, expect, that the extra time and effort required to plan computer-controlled laboratory exercises will be demonstrably more successful in teaching the material than conventional methods.

The results of the present experiment suggest cautious optimism for the use of computer-controlled experimental procedures in our research investigations and laboratory courses. The recall data presented here showed evidence of release from PI in both traditional and computer versions, although the magnitude of the effect differs somewhat. More important, the students seem to learn as much and find the experience equally enjoyable in both versions. There were some inevitable tradeoffs: The computerized version of RELEASE FROM PI is twice as fast to complete as the traditional procedure, but (at least in our learning laboratory) fewer students can participate at once.

A final word of caution is suggested by the fact that this comparison could be made at all. In many cases we have found ourselves writing software for laboratory demonstrations that are almost exact replicas of the traditional "hands-on" demonstrations we used to employ (for example, RELEASE FROM PI). Experience suggests that it may require extra effort to utilize the unique capabilities of computers as instructional tools in undergraduate education (e.g., rapid randomization and counterbalancing, timing of responses, storing large sets of stimulus materials, dynamic visual displays, automatic scoring procedures and interactive feedback). 


\section{REFERENCES}

Lowe, D. C. A Winchester hard-disk integrated computer-assisted instructional laboratory: Hardware and data management considerations. Behavior Research Methods \& Instrumentation, $1983,15,181-182$.
SPIvEY, J. E. Software development for computer-assisted instruction in experimental psychology. Behavior Research Methods \& Instrumentation, 1983, 15, 183-186.

Wickens, D. D. Characteristics of word encoding. In A. W. Melton \& E. Martin (Eds.), Coding processes in human memory. Washington, D.C: Wiley, 1972. 